\title{
Motivação e docência no ensino especial: um estudo com professoras do distrito federal
}

\author{
Carlos Manoel Lopes Rodrigues* \\ Karem Kolarik** \\ Yasminne Cristina Alves Bomfim *** \\ Ana Carolina da Silva**** \\ Ane Caroline da Silva**** \\ Ana Luzia de Queiroz Cunha Guimaräes******
}

\section{Resumo}

O estudo da motivação no trabalho é tema recorrente, mas pouco explorado em relação a motivação do professor e, em menor grau ainda, em um contexto laboral táo peculiar quanto a educação especial. Tendo em vista a relevância social do trabalho docente nesta modalidade de ensino e suas especificidades, este estudo objetivou a investigação da motivaçáo e seus fatores condicionantes de docentes do ensino especial. Participaram pesquisa 33 professoras de ensino especial da rede pública do Distrito Federal, respondendo a Medida de Motivação no Trabalho, composta por seçóes que avaliam três dimensôes componentes da motivação para trabalhar: Seção I avaliando a valência (o que é valorizado pelo indivíduo); Seção II direcionada a avaliação da instrumentalidade (percepção do trabalho como forma de alcançar seus objetivos); e Seção III mensurando a expectância (percepção de como seus esforços são recompensados pelo trabalho atual). Os Escores Gerais de Motivação obtidos para a amostra apresentaram um nível de motivação considerado alto $(\bar{x}=89,36)$, entretanto os escores individuais indicaram uma variação significativa $\left(\sigma=20,70 ; s^{2}=428,50\right)$, e quando agrupadas as participantes por nível obteve-se $60,61 \%$ de escores altos; $36,36 \%$ de escores mediados e 3,03\% de escores baixos. A análise detalhada dos escores por seçôes e itens do instrumento indicou que os altos níveis de motivação das participantes sofrem influência negativa das condições de trabalho. A avaliação dos itens relacionados a autonomia, a relação com chefias e a participação nas decisóes da organização, apresentaram maior potencial de diminuição da motivação global destas profissionais.

Palavras-chave: Trabalho docente; Educação Especial; Motivação.

\footnotetext{
* Professor da Universidade Católica de Brasília, Brasília, Distrito Federal, Brasil.

** Professora da Faculdade Projeção, Brasília, Distrito Federal, Brasil.

*** Discente do curso de Administração da Faculdade Projeção, Brasília, Distrito Federal, Brasil.

**** Discente do curso de Administração da Faculdade Projeção, Brasília, Distrito Federal, Brasil.

*****Discente do curso de Administração da Faculdade Projeção, Brasília, Distrito Federal, Brasil.

******Discente do curso de Administração da Faculdade Projeção, Brasília, Distrito Federal, Brasil.
} 


\section{Motivation and teaching in special education: study with teachers of the Distrito Federal}

\section{Abstract}

The study of motivation at work is a recurring theme, but little explored in relation to teacher motivation and to a lesser extent also in a work context as peculiar as special education. Considering the social relevance of teaching this type of education and its specificities, this study aimed to investigate the motivation and their conditioning factors of special education teachers. Participated research 33 special education teachers from public schools of the Federal District, responding to measure Motivation at Work, composed of sections that evaluate three components of motivation dimensions to work: Section I evaluating the valence (which is valued by the individual); Section II directed the evaluation of instrumentality (perception of work as a way to reach your goals); and Section III measuring the Expectancy (perception of how your efforts are rewarded by the current job). Motivation of the General scores obtained for the sample showed a level of motivation considered high $\left(\bar{x}_{=}=89,36\right)$, but the individual scores indicated a significant variation $(\sigma=20,70 ; s 2=428,50)$, and when grouped participants per level was obtained $60.61 \%$ of high scores; $36.36 \%$ of mediated scores and $3.03 \%$ of low scores. A detailed analysis of the scores for sections and items of the instrument indicated that high levels of motivation of the participants suffer negative influence of working conditions. The evaluation of items related to autonomy, relationship with managers and participation in organizational decisions, had greater potential for reducing the overall motivation of these professionals.

Keywords: Teaching work; Special Education; Motivation.

\section{Introdução}

A motivação é um dos temas clássicos de estudo da Psicologia e da Educação, com ênfase no estudo do papel do professor como agente de promoção da motivação no processo ensino-aprendizagem, mas quando analisada a questáo da motivação docente em relação aos aspectos organizacionais e do trabalho docente em si, observa-se uma diminuição da produção sobre motivação (VISEU et al, 2015).

A assunção da importância do papel do professor no processo ensino-aprendizagem é comum na literatura, com maior destaque em situaçôes onde o desempenho do professor é considerado elemento central do processo, como no caso da educação especial (DĂNESCU; IORDĂCHESCU, 2012; PORTO; OLIVEIRA, 2010), sendo a motivação uma variável importante para entendimento do comportamento dos indivíduos no ambiente laboral, principalmente pela crença de que "altos níveis de motivação são capazes de melhorar o desempenho e garantir ganhos de produtividade" (QUEIROGA; BORGES-ANDRADE, 2015, p. 165).

Tendo em vista este cenário, a investigação das variáveis condicionantes do comportamento organizacional se mostra necessária para o entendimento das relaçôes que os indivíduos estabelecem com seu trabalho e o reflexo destas relaçóes em 
sua saúde, bem-estar e no próprio desempenho no trabalho; investigação esta que assume relevância maior quando se observa a importância social do trabalho docente, principalmente quando consideramos o trabalho docente realizado em condiçóes tão peculiares quanto o da educaçáo especial.

No intuito de contribuir para compreensão das configurações que o trabalho docente assume nesse contexto de trabalho tão diferenciado, este estudo tem por objetivo precípuo a investigação da motivação no trabalho destes docentes que atuam na educação especial.

Para alcance de seu objetivo, este artigo estrutura-se a partir de uma breve apresentação sobre motivação e trabalho docente, seguida de uma contextualização do trabalho do professor no ensino especial. No tópico sobre metodologia são apresentadas as características da amostra, o instrumento de pesquisa, bem como os procedimentos de coleta e análise de dados. Tendo em vista as limitaçóes de espaço os resultados e sua discussáo são apresentados em único tópico seguido pelas consideraçôes finais onde os principais achados são sintetizados e as limitaçóes do trabalho e perspectivas de continuidade são elencadas.

\section{Motivação e Trabalho Docente}

Tradicionalmente a motivação é um dos temas mais importantes no campo na investigaçáo da conduta humana no trabalho, atraindo pesquisadores, gestores, profissionais de recursos humanos de diversas áreas e formaçôes no intuito de esclarecer e determinar quais fatores desencadeiam e mantem o comportamento humano direcionado ao trabalho nas organizaçóes (ROBBINS; JUDGE; SOBRAL, 2010; PINDER, 2008).

No campo de estudo da motivação a determinação das variáveis individuais e organizacionais que conduzem ao desempenho de alto padrão toma corpo a partir dos anos $60^{1}$ com destaque para o modelo proposto por Vroom (1964), de inspiração cognitivista, onde a avaliaçáo do indivíduo das consequências de suas açôes em interação com suas expectativas conduziriam a ação dos indivíduos. Neste modelo a interação de três cogniçóes distintas - valência, instrumentalidade e expectância - resultaria na escolha da conduta adotada.

A valência consiste na atribuição de um valor positivo ou negativo a determinada consequência de um comportamento, em outra palavras, o estabelecimento do que é valorizado, e consequentemente desejado, por cada indivíduo. Já a instrumentalidade é uma crença de que um comportamento específico gerará um determinado resultado, por exemplo, que entregar atividades dentro do prazo reverterá em alguma recompensa desejada. Por expectativa concebe-se o grau com que o indivíduo consegue antecipar as recompensas de seus comportamentos. Como indicado por Gondim e Silva (2014, p. 180) "a suposição de Vroom é a de que as pessoas decidem sobre suas açóes de modo instrumental, procurando maximizar seu prazer e seus ganhos e minimizar seu desprazer e suas perdas". 
Carlos Manoel Lopes Rodrigues - Karem Kolarik - Yasminne Cristina Alves Bomfim - Ana Carolina da Silva - Ane Caroline da Silva - Ana Luzia de Queiroz Cunha Guimarães

Do ponto de vista prático, o modelo de Vroom (1964) prevê que uma pessoa agirá com maior dedicação no trabalho quanto maior for sua atração pelos resultados possíveis desta dedicação (valência); quanto maior for sua crença que a dedicação será recompensada naquele dado local de trabalho (expectância); e escolhendo ações que ela avalie como meio de demonstração efetiva desta dedicação (instrumentalidade).

O modelo de Vroom tem se mostrado influente no campo de estudo do comportamento humano no trabalho tanto no contexto internacional (VAN EERDE; THIERRY, 1996; PINDER, 2010), quanto no nacional (QUEIROGA; BORGES -ANDRADE, 2015), e que para o entendimento do trabalho docente pode lançar luz sobre questôes sobre quais variáveis fazem a mediação do nível motivacional, além de permitir identificar a relação entre os valores pessoais e recompensas organizacionais, uma vez que "valores são potentes ativadores, especialmente porque estão carregados de afetos, ou seja, há um forte investimento emocional em açôes congruentes com tais valores" (GONDIM; SILVA, 2014, p. 195)

O estudo da motivação no trabalho docente é de especial interesse quando atentamos à relevância deste trabalho para nossa sociedade, e cuja investigação se torna crucial para melhoria do bem-estar destes profissionais, da própria gestão e no desempenho de instituiçôes de ensino bem como a formulação e ou adequação de políticas públicas para educação (VISEU et al, 2015), sendo a motivação docente determinante, por exemplo, na escolha da profissão e permanência na profissão (PAULICK; RETELSDORF; MÖLLER, 2013; JESÚS et al, 2011), além de necessária em alto nível para a formação continuada (CARLOTTO et al, 2012) e produtividade acadêmica (ESTES; POLNICK, 2012).

Bentea e Anghelache (2012) em um estudo sobre a motivação e satisfação no trabalho com professores, os autores concluem que os níveis destas variáveis podem ser incrementados com a criação de mais oportunidades para professores de assumirem as suas responsabilidades profissionais. A partir da promoção do reconhecimento da contribuiçẫo e esforço de cada membro da organização, com criação de oportunidades para alcançar a autorrealização, apoiando o desenvolvimento de sua carreira profissional e identidade como professores, com incentivo de desempenho no trabalho, além da busca por um ambiente social salutar e incentivo ao trabalho em equipe e as relaçóes interpessoais positivas.

Em um estudo comparativo entre professores brasileiros e portugueses Jesús, et al (2011) apontam para relação entre níveis motivacionais e tendência a permanência na profissão docente, relação também encontrada por Paulick, Retelsdorf e Möller (2013), cuja pesquisa aponta, ainda, para a relação positiva entre a motivação para a escolha da profissão, o desempenho docente e as conquistas profissionais dos professores, mediadas pelas condiçôes de trabalho.

Este cenário, onde a motivação no caso do trabalho docente apresenta um nível significativo de dependência das variáveis organizacionais, nelas inclusas as condiçôes de trabalho, as recompensas organizacionais (financeiras e não financeiras), a autonomia, e as relaçôes socioprofissionais, indica que a investigação da motivação 
docente deve ser estendida aos vários contextos de trabalho e suas especificidades, o que nos remete ao trabalho docente na Educação Especial, área tão idiossincrática da práxis do professor.

\section{A docência no ensino especial}

No atual contexto, a educação especial é entendida como a modalidade de educação caracterizada na Lei de Diretrizes e Bases da Educação Nacional, com a redação alterada pela Lei no 12.796 , de 4 de abril de 2013 , como aquela "oferecida preferencialmente na rede regular de ensino, para educandos com deficiência, transtornos globais do desenvolvimento e altas habilidades ou superdotaçáo" (BRASIL, 2013), implicando em seu maior fator distintivo em educação ofertada nas demais etapas e modalidade de ensino - as especificidades de seus educandos que requerem práticas pedagógicas diferencias e que dependem principalmente de um docente motivado para o processo pedagógico.

Neste processo, as antigas instituiçôes privadas e filantrópicas vêm sendo substituídas paulatinamente pelo setor público na oferta da educação especial (MENDES, 2010).

Os fatores distintivos da educação especial estão enraizados na política educacional que a funda, sobrepondo funções às já definidas para o ensino regular, flexibilizando e adaptando currículos, além de englobar uma gama de deficiências e necessidades especiais diferentes (GARCIA, 2006; 2013), sendo que o "modelo de atendimento proposto pela atual política faz do professor de educação especial um ser multifuncional" (GARCIA, 2013, p. 115), impondo condiçôes de trabalho distintas da educação regular.

Pode-se afirmar que a organização do trabalho pedagógico na proposta de educaçáo especial na educaçáo básica orienta-se pelo local de atendimento: 1) na escola regular (classe comum, classe especial e sala de recursos); 2) na escola especial (em seus diferentes níveis de atendimento) e 3) em ambiente não escolar (classe hospitalar e atendimento domiciliar). O local de atendimento mantém íntima relação com as funçôes que estão previstas para o atendimento especializado: apoiar, complementar e suplementar e, por último, substituir os serviços educacionais comuns. A diversificação do atendimento possibilita contemplar uma grande variedade de necessidades que possam ser apresentadas pela heterogeneidade dos alunos da educação especial. (GARCIA, 2006, p. 305).

Este quadro implica em um contexto de trabalho tão diversificado que impóem aos professores dificuldades de ordem técnica e de formação, além da confrontação com as condiçôes de trabalho, por vezes distante do ideal e do idealizado (MARQUEZINE; LEONESSA; BUSTO, 2013) colocando a formação continuada com uma necessidade (DĂNESCU; IORDĂCHESCU, 2012), cenário onde a motivação no trabalho surge como fator determinante para o desenvolvimento profissional na área como apontado por Zanelatto e Poker (2012, p. 156): 
Carlos Manoel Lopes Rodrigues - Karem Kolarik - Yasminne Cristina Alves Bomfim - Ana

Carolina da Silva - Ane Caroline da Silva - Ana Luzia de Queiroz Cunha Guimarães

[...] a motivação para fazer o curso está relacionada com as características da fase em que os professores se encontram, tanto no que diz respeito a idade, quanto ao ciclo da trajetória docente e, também, aos aspectos ligados principalmente a atuação profissional do professor, sem contudo desconsiderar os elementos relacionados a formaçáo educacional e vocação pessoal.

No decurso da carreira os aspectos motivacionais continuam importantes ante ao descompasso entre o prescrito e o real no trabalho vivenciado, como encontrado por Ghizoni et al (2015) que ao trabalharem com professores do ensino especial identificaram uma intensa mobilização de recursos subjetivos para lidar com as condiçóes reais do trabalho, que surgem em face ao sofrimento advindo da distância entre o que se prevê para este trabalho e as condiçóes reais de sua execução, constatando-se que, apesar da falta de reconhecimento, "os professores se esforçavam e investiam muita energia, e até mesmo paixão no trabalho" (Ghizoni et al, 2015, p. 87).

Em um contexto similar de exigência de multifuncionalidade aos docentes na educação especial, Dănescu e Iordăchescu (2012), propóem uma seria de competências técnicas e pessoais para o professor da educação especial, competências estas que abrangem uma gama de conhecimentos e funçôes complexas (Quadro 1) que exemplifica o nível de exigência e expectativas depositado sobre estes docentes, e cujo alcance exige um nível de motivação elevado.

Quadro 1 - Competências Didáticas para Educação Especial

\begin{tabular}{|c|c|}
\hline Competências instrumentais & $\begin{array}{l}\text { - Compreender teorias de psicopedagogia } \\
\text { para o tratamento individualizado; } \\
\text { - Projetar e implementar programas de recu- } \\
\text { peração compensatória. }\end{array}$ \\
\hline $\begin{array}{l}\text { Competências de planejamento e organiza- } \\
\text { çáo diferenciada de atividades didáticas }\end{array}$ & $\begin{array}{l}\text { - Elaborar e executar os projetos de tecnolo- } \\
\text { gia didática; } \\
\text { - Projetar apoio educacional adaptado. }\end{array}$ \\
\hline Competências relacionais & $\begin{array}{l}\text { - Demonstrar capacidade relacional empáti- } \\
\text { ca; } \\
\text { - Demonstrar competências relacionais e de } \\
\text { comunicaçáo, incluindo a linguagem especí- } \\
\text { fica das pessoas com deficiência. }\end{array}$ \\
\hline Competências de avaliação & $\begin{array}{l}\text { - Avaliar etiologia, fatores sociais e familiares; } \\
\text { - Desenvolver práticas multidimensionais de } \\
\text { avaliaçáo. }\end{array}$ \\
\hline Competências de aconselhamento & $\begin{array}{l}\text { - Adaptar-se a situaçóes educativas novas; } \\
\text { - Aconselhar grupos e indivíduos; } \\
\text { - Desenvolver estratégias eficazes na família, } \\
\text { nível institucional ou comunidade de prote- } \\
\text { ção aos alunos. }\end{array}$ \\
\hline
\end{tabular}

Fonte: Adaptado de Dănescu e Iordăchescu (2012) 
Em relação aos aspectos motivacionais e sua relação com a saúde e bem-estar docente na educação especial Carlotto et al (2012), em um estudo com 63 professores da educação especial da regiấo Sul do Brasil, encontraram fatores relacionados a motivação (reconhecimento e autonomia) como protetores na Síndrome de Burnout:

Os educadores da escola especial, no momento em que percepcionam uma maior eficácia, actuam com uma maior autonomia e provavelmente, recebem um feedback positivo e um apoio de familiares, colegas e discentes da instituição, apresentando uma maior motivação e entusiasmo pelo trabalho. (CARLOTTO et al, 2012, p. 322).

Tal proposição se alinha com o afirmado por Porto e Oliveira (2010, p. 101), que o professor na educação especial "precisa sentir-se apoiado e acolhido pelas redes de apoio ao processo ensino-aprendizagem", figurando a falta de reconhecimento como fator de sofrimento no trabalho (GHIZONI et al, 2015).

Desta forma, a identificação da relação estabelecida entre o que os docentes da educação especial valorizam e como percebem a realidade efetiva de trabalho, pode auxiliar a entender como a motivação destes profissionais se estrutura, e como traçar estratégias de potencialização dos fatores positivos no trabalho.

\section{Metodologia}

A amostra final foi composta por 33 professoras de ensino especial da rede pública de ensino do Distrito Federal, sendo a coleta de dados realizada no local e horário de trabalho dos participantes, após a apresentação e assinatura do Termo de Consentimento Livre e Esclarecido - TCLE.

Em consonância com o referencial teórico adotado e com os objetivos da pesquisa, as participantes responderam a Medida de Motivação no Trabalho - MMT (QUEIROGA; BORGES-ANDRADE, 2015), composta de 3 seçôes que avaliam três dimensôes componentes da motivação para trabalhar: Seção I avaliando a valência (o que é valorizado pelo indivíduo); Seção II direcionada a avaliação da instrumentalidade (percepção do trabalho como forma de alcançar seus objetivos); e Seção III mensurando a expectância (percepção de como seus esforços são recompensados pelo trabalho atual). Cada dimensão da medida utilizada compóem uma subescala consistente internamente - valência com Alpha de Cronbach de 0,85 e cargas fatoriais entre 0,39 e 0,67; instrumentalidade com Alpha de Cronbach de 0,93 e cargas fatoriais entre 0,44 e 0,85; expectância com Alpha de Cronbach de 0,93 e cargas fatoriais entre 0,70 e 0,88 .

Para obtenção do Escore Geral de Motivação (EGM) foi calculada a média dos resultados para cada respondente por seção da MMT e as médias depois foram multiplicadas entre si, conforme orientação de Queiroga e Borges-Andrade (2015). A interpretação do EGM pautou-se pelos critérios indicados pelos autores (Tabela 1). 
Carlos Manoel Lopes Rodrigues - Karem Kolarik - Yasminne Cristina Alves Bomfim - Ana

Carolina da Silva - Ane Caroline da Silva - Ana Luzia de Queiroz Cunha Guimarães

Tabela 1 - Parâmetros de Interpretação do Escore Geral de Motivação - EGM

\begin{tabular}{|c|c|}
\hline EGM & Interpretaçáo \\
\hline$\leq 45$ & Índice baixo de motivaçáo \\
\hline $46 \geq \mathrm{e} \leq 80$ & Índice mediano de motivação \\
\hline$\geq 81$ & Índice alto de motivação \\
\hline
\end{tabular}

Fonte: Adaptado de Queiroga e Borges-Andrade (2015)

Além do EGM a análise dos resultados em cada subescala foi realizada para obtenção de "um detalhado diagnóstico organizacional ou uma aprofundada interpretação do construto em contexto de trabalho" (QUEIROGA; BORGES-ANDRADE, 2015, p. 170).

Para análise estatística submeteu-se os dados foram tabulados e submetidos a análise no programa Assistat - Assistência Estatística (versão 7.7 beta), para geraçáo das estatísticas descritivas, para análise das médias (Teste t de Student) e das correlaçôes (Pearson), onde foi mantido o nível de significância em 0,05.

\section{Resultados e discussão}

O EGM obtido para a amostra apresentou um nível considerado alto $(\bar{x}=$ 89,36), entretanto os EGMs individuais indicaram uma variação significativa $(\sigma=$ 20,70; s2 = 428,50), e quando agrupadas as participantes por nível do EGM temos 60,61\% de EGMs altos; 36,36\% de EGMs mediados e 3,03\% de EGMs baixos (Gráfico 1).

Gráfico 1 - Distribuição Percentual dos Escores Gerais de Motivação

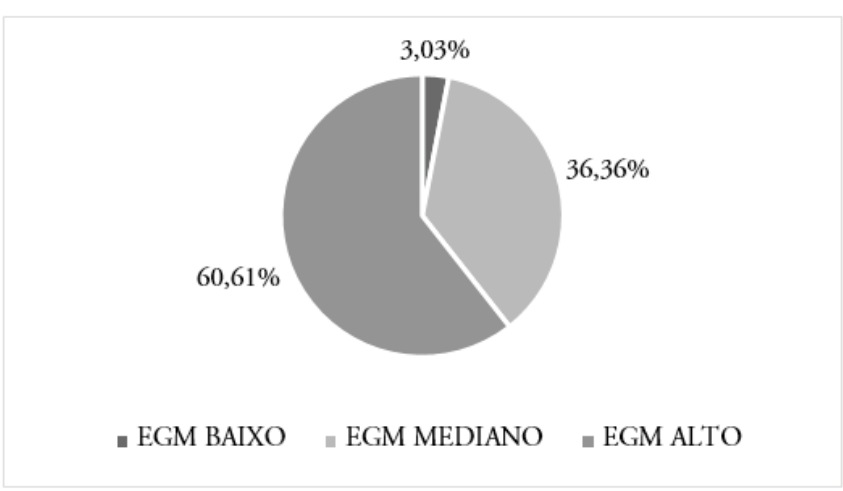

Fonte: Autoria própria

Apesar da prevalência de EGMs altos, quando analisados os escores por seção (Tabela 2) observa-se uma tendência dos escores diminuírem a medida que as seçôes progridem, isto indica que os respondentes, mesmo atribuindo grande valor aos itens expressos na Seção I (Valência), tendem a acreditar menos que seus esforços no traba- 
lho lhe permitiriam alcançar o que valorizam (instrumentalidade) e gerando menos expectativas quanto a isso no trabalho atual (expectância) - Gráfico 2.

Tabela 2 - Estatística Descritiva por Seção da MMT

\begin{tabular}{|lr|lr|ll|}
\hline \multicolumn{2}{|c|}{ Valência } & \multicolumn{2}{c|}{ Instrumentalidade } & \multicolumn{2}{c|}{ Expectância } \\
\hline Média & 4,59 & Média & 4,49 & Média & 3,80 \\
\hline Mediana & 4,67 & Mediana & 4,50 & Mediana & 3,75 \\
\hline Modo & 4,50 & Modo & 5,00 & Modo & 4,38 \\
\hline Desvio padrão & 0,32 & Desvio padrão & 0,44 & Desvio padrão & 0,44 \\
\hline Variância da amostra & 0,10 & Variância da amostra & 0,19 & Variância da amostra & 0,19 \\
\hline Mínimo & 3,42 & Mínimo & 3,17 & Mínimo & 2,63 \\
\hline Máximo & 5,00 & Máximo & 5,00 & Máximo & 4,38 \\
\hline $\begin{array}{l}\text { Nível de confiança } \\
\text { (95,0\%) }\end{array}$ & 0,11 & $\begin{array}{l}\text { Nível de confiança } \\
(95,0 \%)\end{array}$ & 0,16 & $\begin{array}{l}\text { Nível de confiança } \\
(95,0 \%)\end{array}$ & 0,16 \\
\hline
\end{tabular}

Fonte: Autoria própria

Gráfico 2 - Escores Médios por Dimensão componente da MMT

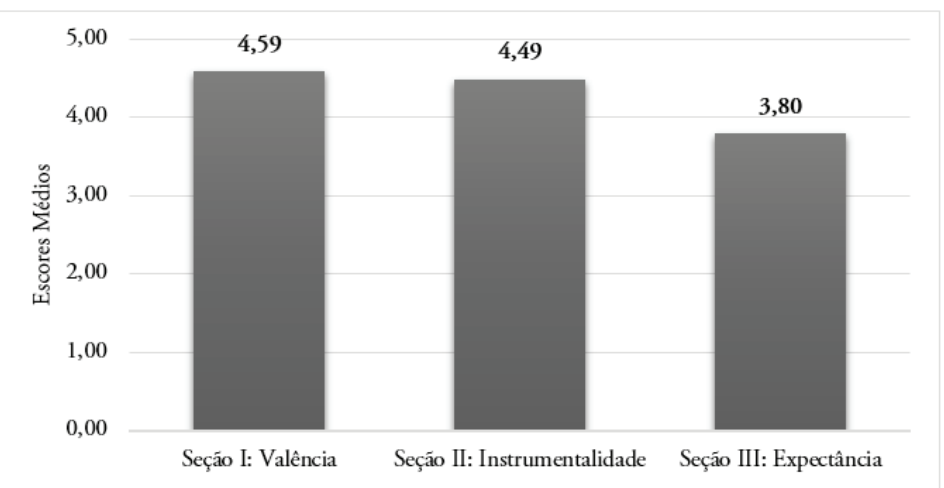

Fonte: Autoria própria

A análise da diferença entre os escores médios das seçôes realizada pela comparação em pares no Teste $t$ de Student $(\alpha=0,05 ; \varphi=64)$ retornou valores considerados significativos nas comparaçôes entre a expectância as duas demais seçôes (Tabela 3). Já a comparaçáo dos escores médios obtidos em valência e instrumentalidade não se revelaram significativos. 
Carlos Manoel Lopes Rodrigues - Karem Kolarik - Yasminne Cristina Alves Bomfim - Ana

Carolina da Silva - Ane Caroline da Silva - Ana Luzia de Queiroz Cunha Guimarães

Tabela 3 - Resultados do Teste t de Student para Escores das Seçóes da MMT

\begin{tabular}{|c|c|c|c|}
\hline & Valência & Instrumentalidade & Expectância \\
\hline Valência & 0 & - & - \\
\hline Instrumentalidade & 1,04 & 0 & - \\
\hline Expectância & 8,40 & 6,41 & 0 \\
\hline
\end{tabular}

Fonte: Autoria própria

Assumindo a significância da diferença dos escores relativos à expectância, a submissão dos escores à análise da correlação (Coeficiente de Pearson) entre as dimensôes avaliadas na MMT, indicou uma correlação positiva entre as dimensôes (Tabela 4) - a variação em uma dimensão afeta as demais no mesmo sentido do sinal da variação - neste caso específico, os escores mais baixos obtidos na dimensão expectância induzem a uma redução nos escores das demais dimensôes, principalmente na instrumentalidade. As condições de trabalho afetam negativamente o nível motivacional das participantes, uma vez que a expectância está relacionada diretamente ao trabalho atual dos participantes (QUEIROGA; BORGES-ANDRADE, 2015).

Tabela 4 - Índices de Correlação de Pearson entre Escores Obtidos na MMT por Seção

\begin{tabular}{|c|c|c|c|}
\hline & Valência & Instrumentalidade & Expectância \\
\hline Valência & 1 & - & - \\
\hline Instrumentalidade & 0,78 & 1 & - \\
\hline Expectância & 0,58 & 0,73 & 1 \\
\hline
\end{tabular}

Fonte: Autoria própria

Considerando que a MMT é constituída por itens que se referem à autorrealização pessoal e profissional, às recompensas financeiras, à autonomia, e ao reconhecimento social, os altos escores na dimensão valência e instrumentalidade se alinham ao encontrado por Zanellato e Poker (2012) quanto a diversidade de fatores valorizados por professores da educaçáo especial, sendo estes fatores distribuídos em três categoria motivacionais - profissional, educacional e pessoal.

A análise detalhada dos escores por item componente da seção III (expectância) indicou que os itens referentes à participação nas decisões da organização $(\bar{x}=$ $\left.3,12, \sigma_{=} 0,95\right)$, reconhecimento $(\bar{x}=3,36, \sigma=0,60)$ e relação com chefias $(\bar{x}=3,85$, $\sigma=0,61$ ) obtiveram menores escores médios, induzindo o rebaixamento dos escores médios de toda dimensão expectância. Resultados que reforçam a necessidade de autonomia apontada por Carlotto et al (2012) e de apoio institucional aliado a relaçóes socioprofissionais salutares defendido por Dănescu e Iordăchescu (2012) e Porto e Oliveira (2010) como essenciais para o trabalho do professor na educação especial.

A falta de autonomia pode ser analisada a partir de duas possibilidades não excludentes, por um lado a forma de organização da educação especial dada pelas 
políticas educacionais que impõem modelos e fazeres, nem sempre consistentes, para estes docentes (GARCIA, 2013; 2006), por outro a fatores da cultura organizacional típicos do serviço público - centralização e burocracia, contexto no qual grande parte da educação especial se insere.

Especialmente quanto aos baixos escores relativos ao reconhecimento no trabalho, é necessário indicar ser este um fator apontado por Ghizoni et al (2015) como potencial fonte de vivências de sofrimento no trabalho e, ainda, constituir um fator protetivo à saúde destes profissionais (CARLOTTO et al, 2012), necessitando um olhar urgente de gestores educacionais.

\section{Considerações finais}

Encontrar altos níveis motivacionais nas dimensôes é especialmente positivo ao se analisar a importância do trabalho realizado na educação especial, ante o grau de investimento pessoal e de dedicação que este labor requer, entretanto a identificaçáo dos fatores que interferem nestes níveis de motivação, pode se revelar mais útil, por "revelar a fonte de baixos indicadores de motivação" (QUEIROGA; BORGES -ANDRADE, 2015, p. 171), permitindo o planejamento e aplicaçáo de açóes que revertam ou minimizem estes impactos negativos, não só sobre a produtividade, mas também sobre o bem-estar geral dos trabalhadores.

Dentro do modelo proposto por Vroom (1964), este efeito negativo das condiçóes gerais de trabalho sobre a expectância dos sujeitos representa um risco de rebaixamento no nível motivacional geral do trabalhador, já que ao reduzir a expectativa de obtenção de resultados que valorize, o indivíduo escolherá menos condutas que acreditava eficazes para obtenção destas recompensas, efeito já percebido por Estes e Polnick (2012) ao avaliarem os efeitos da motivaçáo docente na produtividade em condiçóes instáveis de trabalho e por Paulick, Retelsdorf e Möller (2013) ao avaliarem o efeito das práticas de gestão no nível motivacional de docentes.

Em um contexto onde estas professoras precisam encontrar e aplicar práticas próprias para resoluçáo das situaçóes a que estão expostos cotidianamente (GHIZONI et al, 2015; CARLOTTO et al, 2012), a autonomia e a possibilidade de participarem das decisóes assumem um papel central no fazer docente, o que exige repensar as práticas atuais de gestáo e prescrição do trabalho pedagógico, em busca de uma gestấo mais democrática do espaço escolar e promoção de relaçóes socioprofissionais salutares.

Reconhecer o trabalho realizado, por fim, se mostra como ação urgente por parte de chefias e comunidade escolar, mas que também deve se converter em açóes concretas nas políticas da educação especial, sob pena de evasão de docentes e declínio da qualidade da educação especial.

\section{Referências}

BENTEA, C.-C.; ANGHELACHE, V.. Teachers' motivation and satisfaction for professional activity. Procedia - Social and Behavioral Sciences, v. 33, p. 563 - 567, 2012. 
Carlos Manoel Lopes Rodrigues - Karem Kolarik - Yasminne Cristina Alves Bomfim - Ana

Carolina da Silva - Ane Caroline da Silva - Ana Luzia de Queiroz Cunha Guimarães

BRASIL. Lei no 12.796, de 4 de abril de 2013. Altera a Lei no 9.394, de 20 de dezembro de 1996, que estabelece as diretrizes e bases da educação nacional, para dispor sobre a formação dos profissionais da educação e dar outras providências. Diário Oficial da República Federativa do Brasil, Brasília, DF, 5 abr. 2013. Disponível em: <http://www.planalto.gov.br/CCIVIL_03/_Ato2011-2014/2013/Lei/L12796.htm\#art1>. Acesso em: 27 ago. 2015.

CARLOTTO, M. S.; LIBRELOTTO, R.; PIZZINATO, A.; BARCINSKI, M.. Prevalência e factores associados à Síndrome de Burnout nos professores de ensino especial. Análise Psicológica, v. 30, n. 3, p. 315 - 32, 2012

DĂNESCU, E.; IORDĂCHESCU, D.. The scholar integration of students with special needs - a regional approach. Procedia - Social and Behavioral Sciences, v. 33, p. 588 - 592, 2012.

ESTES, B.; POLNICK, B.. Examining Motivation Theory in Higher Education: An Expectancy Theory Analysis of Tenured Faculty Productivity. International Journal of Management, Business, and Administration, v. $15, \mathrm{n}, 1$, p. $1-7,2012$.

GARCIA, R. M. C.. Política de educação especial na perspectiva inclusiva e a formação docente no Brasil. Revista Brasileira de Educaçáo, v. 18, n. 52, 2013.

Políticas para a educação especial e as formas organizativas do trabalho pedagógico. Revista Brasileira de Educaçáa Especial, v.12, n.3, p.299 - 316, 2006.

GHIZONI, L. G.; MEDEIROS, S. N.; CARVALHO, G. M., MORAES, R. D.; SANTANA, P. M.; MAGNUS, C. N.; MERLO, A. R. C..; LIMA, P. A. M. L.; MENDES, A. M.. Clínica psicodinâmica do trabalho: a prática em diversos contextos de trabalho. Desafios: Revista Interdisciplinar da UFT, v. 1, n. 1, p. 74 - 92, 2014.

GONDIM, S. M.; SILVA, N.. Motivação no trabalho. Em: ZANELLI, C.; BORGES-ANDRADE, J. E.; BASTOS, A. B.. Psicologia, Organizaçóes e Trabalho no Brasil. 2a. Ed., Porto Alegre: Artmed, 2014, p. 171 - 200.

JESÚS, S. N.; MOSQUERA, J.; STOBAUS, C.; SAMPAIO, A.; REZENDE, M.; MASCARENHAS, S.. Avaliação da motivação e do bem/ mal-estar dos professores: estudo comparativo entre Portugal e o Brasil. Amazônica: Revista de Psicopedagogia, Psicologia Escolar e Educaçáo, v. 7, n. 2, p. 7 - 18, 2011.

MARQUEZINE, M. C.; LEONESSA, V. T.; BUSTO, R. M. Professor de Educaçáo Especial e as dificuldades do início da prática profissional. Revista Educaçáo Especial, v. 26, n. 47, p. 699 - 712, 2013.

MENDES, E. G.. Breve histórico da educação especial no Brasil. Revista Educación y Pedagogía, v. 22, n. 57, 2010.

PAULICK, I.; RETELSDORF, J.; MÖLLER, J. Motivation for choosing teacher education: Associations with teachers' achievement goals and instructional practices. International Journal of Educational Research, v. 61, p. $60-70,2013$.

PINDER, C. C.. Work Motivation in Organizational Behavior, 2a. Ed., Nova Iorque: Psychology Press, 2008 .

PORTO, M. D.; OLIVEIRA, M.D.M.. Educaçáo Inclusiva: concepções e práticas na perspectivas de professores. Brasília: Editora Aplicada, 2010.

QUEIROGA, F.; BORGES-ANDRADE, J.E.. Motivação para trabalhar. Em: PUENTE-PALÁCIOS, K.; PEIXOTO, A.L.A. (Orgs.). Ferramentas de Diagnóstico para Organizaçóes e Trabalho: um olhar a partir da psicologia. Porto Alegre: Artmed, 2015, p. 165 - 174.

ROBBINS, S. P.; JUDGE, T. A.; SOBRAL, F.. Comportamento Organizacional: teoria e prática no contexto brasileiro. 14 Ed., São Paulo: Pearson, 2010.

VAN EERDE, W.; THIERRY, H. Vroom's Expectancy Model and Work Related Criteria: A Meta-analysis. Journal of Applied Psychology, v. 81, n. 5, p. 575 - 586, 1996.

VISEU, J. N., JESUS, S.N.; QUEVEDO-BLASCO, R.; RUSC, C. L.; CANAVARRO, J. M. Motivação docente: estudo bibliométrico da relação com variáveis individuais, organizacionais e atitudes laborais. Revista Latinoamericana de Psicologia, v. 47, n. 1, p. 58 - 65, 2015.

VROOM, V. H. Work and motivation. Nova Iorque: Wiley, 1964.

ZANELLATO, D.; POKER, R. B. Formação continuada de professores na educação inclusiva: a motivação em questăo. Revista Ibero-Americana de Estudos em Educaçáo, v. 7, n. 1, p. 147 - 158, 2012. 


\section{Notas}

${ }^{1}$ Para uma revisão detalhada dos modelos teóricos para motivação ver Gondim e Silva (2014) e Pinder (2010).

\section{Correspondência}

Karem Kolarik - Faculdade Projeção, Escola de Formação de Professores. Área Especial Setor C - Norte, Taguatinga Norte (Taguatinga). CEP: 72115700 - Brasília, Distrito Federal, Brasil.

E-mail: carlos.lopes@ucb.br - karem.kolarik@projecao.br - yasminnecris@gmail.com - aninha.ana16@hotmail.com - aninha.ane16@gmail.com - analuziaqueiroz@gmail.com

Recebido em 19 de outubro de 2015

Aprovado em 14 de outubro de 2016 
